\title{
Electron Microscope Observation of the Dislocation Microstructure of Cold Rolled and Annealed Titanium
}

\author{
By Jitsuhiko Ueda* and Toshimi Yamane*
}

\begin{abstract}
The dislocation arrangement of a commercial pure $\mathbf{T i}$ deformed by rolling and annealed was examined using a transmission electron microscope, and the hardness change associated with annealing after cold rolling was also measured. The results obtained may be summarized as follows :

(1) In the specimen as cold rolled, cusp-shape dislocations and loops were frequently observed. U-shape dislocations could be found, though few in number. This fact gives evidence to Price's suggestion that the loops be formed by a cross glide process.

(2) By annealing below about $420^{\circ} \mathrm{C}$, the hardness was scarcely changed, but a noticeable change was observed in the dislocation arrangement.

(3) In the temperature range from $420^{\circ}$ to $520^{\circ} \mathrm{C}$ an abrupt decrease in hardness was observed, but only a slight change took place in the dislocation arrangement.
\end{abstract} (Received April 10, 1964)

\section{Introduction}

Changes in hardness and dislocation arrangement of titanium by cold rolling were investigated, as reported previously by the present authors (1). The results showed that the hardness on the rolling plane increased abruptly with the degree of rolling up to $10 \%$, and increased linearly over $10 \%$ rolling. It was found, moreover, that with increase of the rolling degree, the dislocation density increased, and its shape and distribution became more complicated. It was also found that a great number of dislocation loops were formed by cold rolling. As a follow-up study, this paper deals with results of an experiment on the annealing behavior of the dislocations and loops formed by cold rolling, in an attempt to investigate the relationship between hardness change and dislocation rearrangement that may take place during annealing, changes in dislocation microstructure, and hardness change due to annealing after cold rolling.

There are a few reports on the recovery of hexagonal metals observed by a transmission microscope ${ }^{(2)}$ (3).

Price (2) directly observed the dislocation movement in Cd during the tensile deformation at various temperatures and discovered that above a certain temperature, a partial recovery took place during the deformation process. He also made a direct observation of the interaction between dislocations and inves. tigated the relationship between the deformation temperature and the interaction. Bailey ${ }^{(3)}$ carried out an experiment of the dislocation movement in cold worked $\mathrm{Zr}$ during electron beam heating, and reached a conclusion that the dislocation movement of $\{10 \overline{10}\}$

* Technical Research Laboratory, Hitachi Shipbuilding \& Engineering Co., Ltd., Osaka, Japan.

(1) T. Yamane and J. Ueda : Trans. JIM, 5 (1964), 43.

(2)-P. B. Price : J. Appl. Phys., 32 (1961), 1746; 1750 ; Electron Microscopy and Strength of Crystals, Interscience, (1963), 41.

(3) J:E. Bailey : J. Nuclear Materials, 7(1962), 300. $\langle 11 \overline{2} 0\rangle$ was an important climb phenomenon. No transmission microscope study of recovery in titanium has been reported at present.

\section{Experimental Procedures}

Ti specimens used in this experiment and the method of chemical polishing for electron microscopic observation are the same as those described in a previous paper(1). Annealing of the specimens for hardness tests was carried out at various temperatures for $40 \mathrm{~min}$ after cold rolling, and then the specimens were cooled in air. Vickers hardness on the rolling plane of the specimens was measured at room temperature. The rolled specimens for electron microscope observation were annealed at $420^{\circ}$ or $520^{\circ} \mathrm{C}$ for one hour, and they were made thinner by chemical polishing. The direct observation of these thin foil specimens was made by a transmission electron microscope (HU-10 type) operating at $50 \mathrm{kV}$.

\section{Experimental Results and Discussions}

The specimens of $\mathrm{Ti}$ plates were rolled at room temperature up to $12.0,50.0$ and $67.5 \%$ rolling degrees, and annealed at various temperature for 40 min. Then, the hardness of each specimen was measured at room temperature. The relationship between annealing temperature and hardness is shown in Fig. 1. The hardness of the cold rolled specimens was recovered linearly with increase of the annealing temperature up to about $480^{\circ} \mathrm{C}$, and a noticeable decrease in hardness took place after annealing at $480^{\circ} \sim 600^{\circ} \mathrm{C}$. Above, $600^{\circ} \mathrm{C}$, the hardness was found independent of the annealing temperature.

A dislocation substructure observation of the $5 \%$ cold rolled specimen, after chemically thinned, was carried out by transmission electron microscopy. The results obtained are shown in Photos. 1 and 2 . In 
Photo. 1, a number of dislocation loops and cusp-shape dislocations are observed. Photo, 2 shows a dislocation arrangement in a different area of the $5 \%$ rolled specimen. A number of U-shape dislocations may be observed, but no dislocation loop like that in Photo. 1

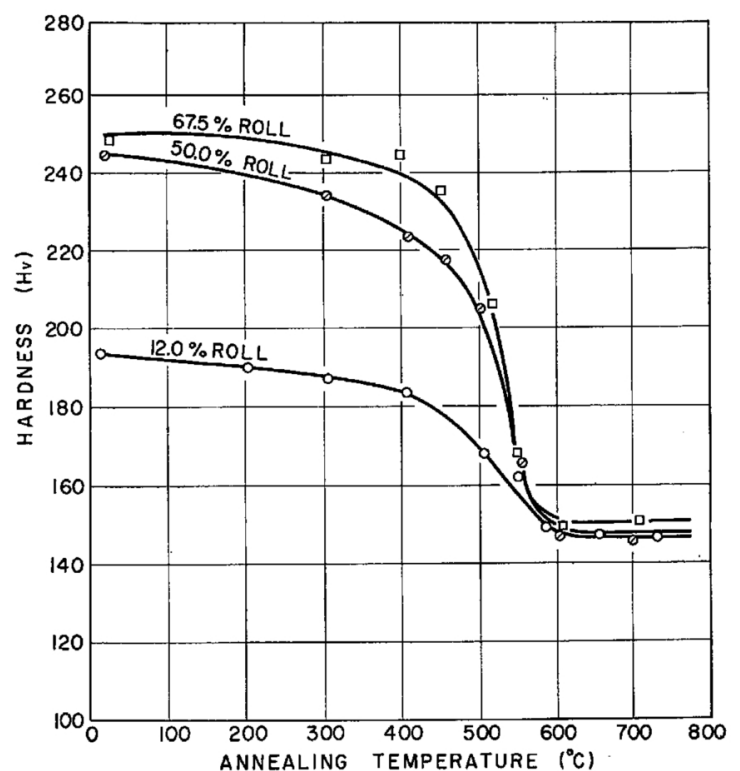

Fig. 1 Relationship between annealing temperature and hardness af ter cold rolling for titanium. Annealing time was 40 minutes.

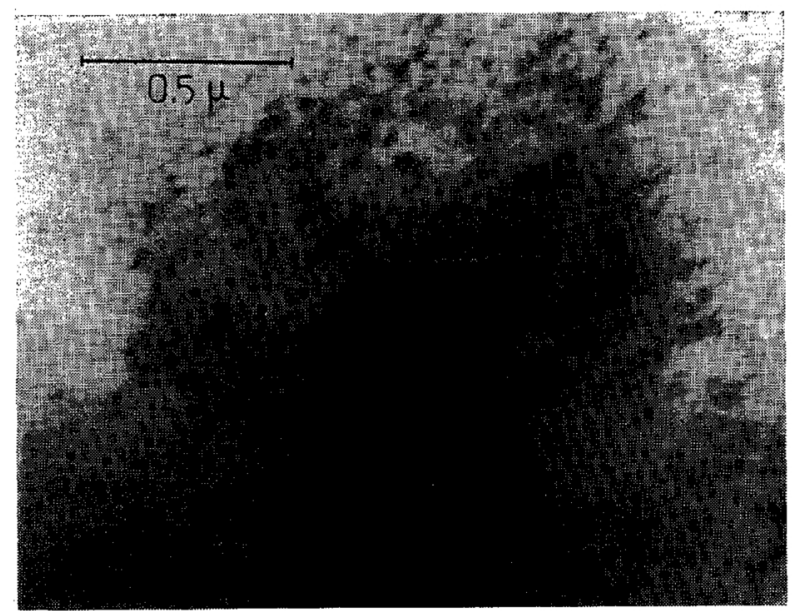

Photo. $15 \%$ cold rolled. Dislocations and loops.

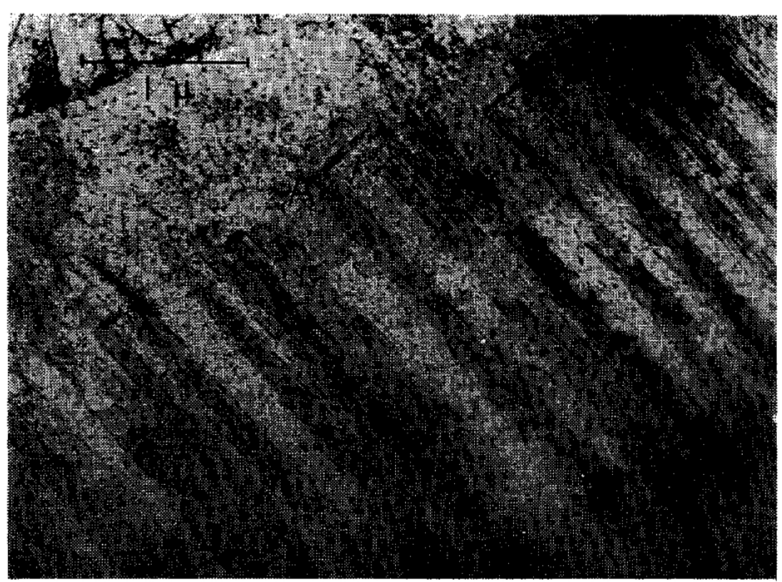

Photo. $25 \%$ cold rolled. A number of U shape dislocations are seen.

cannot be found. One of the U-shape dislocations is exhibited by $\mathrm{A}$ in the photograph. The U-shape dislocations were seldom seen in this experiment : they were believed to be in a stage of the cross glide process proposed dy Price(2). Price directly observed various stages in the formation of a loop by a screw dislocation during deformation of $\mathrm{Cd}$, and called them the cross glide process. As previously reported by increasing the rolling degree, the dislocation density increased, and a number of small dislocation loops were also formed ${ }^{(1)}$.

A dislocation structure observation of the specimens annealed at $420^{\circ} \mathrm{C}$ for one hour after $33.4 \%$ rolling was carried out, the results of which are shown in Photos. 3 and 4. The hardness of the rolled specimen was hardly changed by annealing at $420^{\circ} \mathrm{C}$ as shown in Fig. 1. But a noticeable change in the dislocation substructure was observed. A high density of cusp-shape dislocations and small loops like those observed in the cold rolled specimens were not detected. In Photo. 3, low angle boundaries, one of which is marked $\mathrm{A}$, are seen. The dislocation structure in

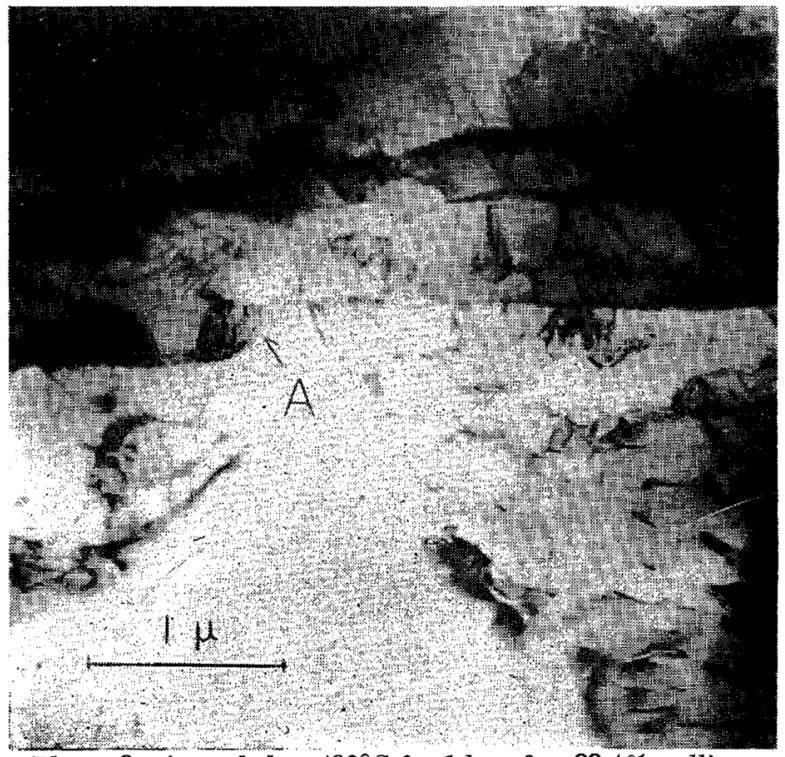

Photo. 3 Annealed at $420^{\circ} \mathrm{C}$ for $1 \mathrm{hr}$ after $33.4 \%$ rolling. A shows a low angle boundary.

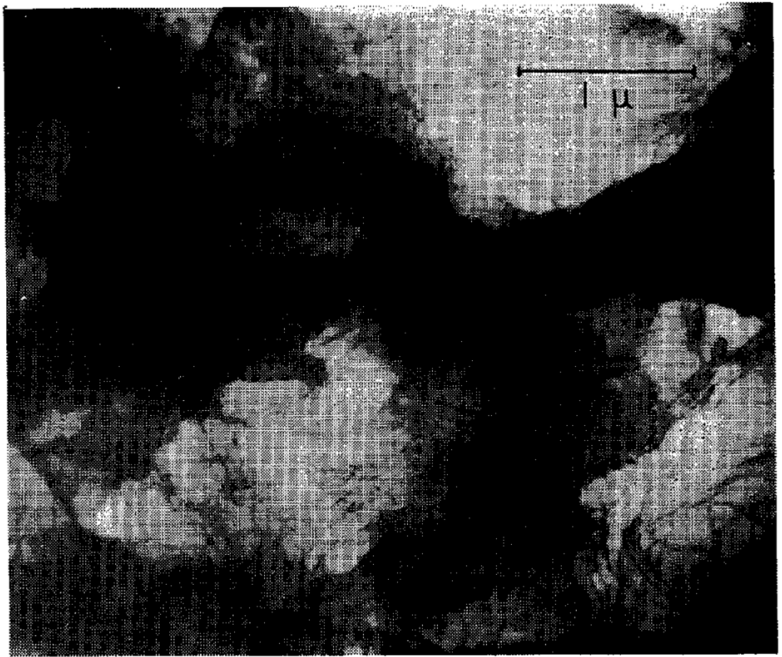

Photo. 4 Annealed at $420^{\circ} \mathrm{C}$ for $1 \mathrm{hr}$ after $33.4 \%$ rolling.

a different area is shown in Photo. 4 ; This structure is found to be noticeably different from that observed in the cold rolled specimen, although the dislocations 
still remain unstable. $\mathrm{Keh}^{(4)}$ recently made a study of the dislocation arrangement in recovered alpha iron by transmission electron microscopy, and suggested that the flow stress during the recovery was

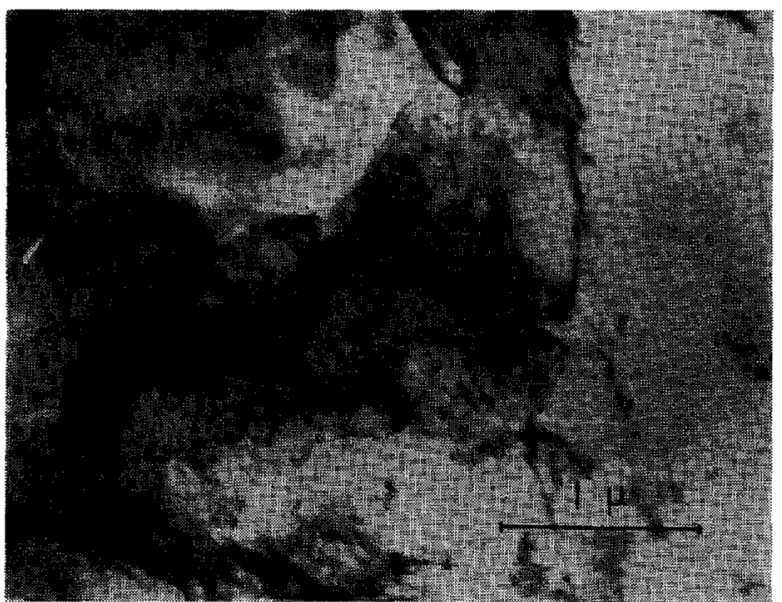

Photo. 5 Annealed at $520^{\circ} \mathrm{C}$ for 1 hour after $33.4 \%$ rolling.

not completely controlled by the dislocation density.

The dislocation structure observation was made on

(4) A.S. Keh : Direct Observation of Imperfections in Cry stals, (AIME, 1962), 213. a specimen annealed at $520^{\circ} \mathrm{C}$, after $33.4 \%$ cold rolling. The result obtained is shown in Photo. 5. As shown in Fig. 1, a sharp drop in hardness occurred in the temperature range from $420^{\circ}$ to $520^{\circ} \mathrm{C}$, whereas the dislocation arrangement appeared not to considerably change during annealing in the same range of temperature. Low angle boundaries and dislocations as those frequently observed in the annealed specimens are seen in Photo. 5 .

\section{Summary}

The results of the present experiment may be summarized as follows :

(1) Cusp-shape dislocations and loops were frequently observed in the cold rolled specimen. The existence of U-shape dislocations, though few in number, observed in the cold rolled specimen may suggest that the loops are formed by a cross glide process as proposed by Price.

(2) By annealing below about $420^{\circ} \mathrm{C}$, the hardness was hardly changed, but a noticeable change in the dislocation arrangement was observed.

(3) An abrupt decrease in hardness was observed after annealing from $420^{\circ}$ to $520^{\circ} \mathrm{C}$, but only a slight change was observed in the dislocation arrangement. 